\begin{tabular}{|c|c|c|}
\hline 7 & $\begin{array}{c}\text { European Association for the } \\
\text { Development of Renewable Energies, Environment } \\
\text { and Power Quality (EA4EPQ) }\end{array}$ & $\begin{array}{l}\text { International Conference on Renewable Energies and Power Quality } \\
\text { (ICREPQ'12) } \\
\text { Santiago de Compostela (Spain), 28th to 30th March, } 2012\end{array}$ \\
\hline
\end{tabular}

\title{
Improved wind forecasting with wavelets
}

\author{
J.A. Domínguez-Navarro ${ }^{1,2}$, J.S. Artal ${ }^{1}$, H. Bludsweit ${ }^{2}$, J.L. Bernal-Agustín ${ }^{1}$ and R. Dufo ${ }^{1}$ \\ ${ }^{1}$ Department of Electrical Engineering \\ E.I.N.A., Zaragoza University \\ Campus Río Ebro - María de Luna, 3, 50018 Zaragoza (Spain) \\ Phone number:+0034 976 762401, e-mail: jadona@unizar.es \\ ${ }^{2}$ Circe Foundation \\ Campus Río Ebro - Mariano Esquilor, 15, 50018 Zaragoza (Spain) \\ Phone number:+0034 976761863
}

\begin{abstract}
An important consequence of a high wind penetration and the difficulty to predict the power generated is the need to entrust the coverage of a large power variations to power spinning reserve. A forecasting system of generation would resolve, at least in part, this problem. The wind variability has a significant negative influence on the forecast models. To avoid the influence of variability, we applied a wavelet filter that can work with softer signals. The results improve significantly when wavelet filtering is applied.
\end{abstract}

\section{Key words}

Wind power, forecasting, wavelets.

\section{Introduction}

The expectations of increase in the coming years of the installed wind power is necessary to have tools to predict wind generation with different time horizons, so that system operation can be performed under adequate conditions of safety and economy.

An important consequence of a high wind penetration and the difficulty to predict the power generated is the need to entrust the coverage of a large power variations to power spinning reserve. In addition, the obligation to purchase all the wind power is produced, requires distributors have difficulty adjusting their purchases in the electricity market.

A forecasting system of generation would resolve, at least in part, this problem. The operating system needs to have a means to forecast and estimate the hourly energy to be generated at wind farms in the short term, in order to reduce the deviations in the generation and reserve programs, and minimize the impact on the operation and in the electricity market, making it more reliable and secure. Over the years, various authors have developed numerous methods of forecasting wind or the power supplied by wind farms.

The systems used for forecasting are: statistical methods and neural networks. Table I summarizes the characteristics of some of these methods. The first column identifies the authors, in the second column indicates if they make the forecast wind velocity $(\mathrm{V})$ or power output (P) in the third column indicates the method used, in the fourth column the forecast horizon, and in the last column the improvement achieved.

Table I. - Forecasting methods

\begin{tabular}{|c|c|c|c|c|}
\hline Authors & Var. & Method & $\begin{array}{c}\text { Temporal } \\
\text { series }\end{array}$ & Improve \\
\hline$[1]$ & V-P & Box-Jenkins & -- & -- \\
\hline$[2]$ & V & Kalman filter & $1^{\prime}$ & $4-10 \%$ \\
\hline$[3]$ & V & ARMA & $\begin{array}{c}20^{\prime \prime}\left(2^{\prime \prime}\right)- \\
0^{\prime}\left(1^{\prime}\right)\end{array}$ & $5-12 \%$ \\
\hline$[4]$ & V & Kalman filter & -- & -- \\
\hline$[5]$ & P & ARMA & $2 \mathrm{~h}\left(10^{\prime}\right)$ & $12 \%$ \\
\hline$[6]$ & P & ARMA & $2 \mathrm{~h}\left(10^{\prime}\right)$ & $=$ \\
\hline$[7]$ & P & AR(3) & -- & -- \\
\hline$[8]$ & P & ANN & $10^{\prime \prime}$ & $=$ pers. \\
\hline$[9]$ & V-P & ANN & $1^{\prime}-10^{\prime}$ & $11 \%-8 \%$ \\
\hline$[10]$ & & ANN & & \\
\hline$[11]$ & P & ANN & $2-3 \mathrm{~h}\left(10^{\prime}\right)$ & $9-12 \%$ \\
\hline$[12]$ & V-P & Spatial/ANN & $2 \mathrm{~h}\left(5^{\prime}\right)-$ & $15-25 \%$ \\
\hline$[13]$ & P & ANN & $\left.10^{\prime}\right)$ & $0,3-4 \%$ \\
\hline$[14]$ & V & ANN & $1^{\prime}-1 \mathrm{~h}$ & -- \\
\hline$[15]$ & V & ARMA & $1 \mathrm{~h}-10 \mathrm{~h}$ & $12-20 \%$ \\
\hline \multicolumn{4}{|r}{} \\
\hline
\end{tabular}

Section 2 describes the assumptions about the forecasting methods used. Section 3 describes briefly the concepts of the wavelet transform. Section 3 shows how to apply the methods of prediction. The following section discusses the results and section 5 summarizes the conclusions. 


\section{Forecasting model}

The attempt to solve the problem of forecasting has led to different models, from classical models (persistence model) to advanced models (regression models, fuzzy and neural). In this paper we will use the persistence model and regression model.

Persistence model: This classic model presents great simplicity and requires minimal effort. His forecast is to assume that the variable for which you are trying to predict its value, remains its value from a moment of time to another. This means that the value of the variable at the instant of time $t+1$ is equal to the value of the variable at the moment $\mathrm{t}$.

Multiple regression model: This model studies the relationship between a dependent variable and a set of independent variables. Knowledge of these relationships is used to predict future values of the dependent variable when only the values of independent variable are known.

The expression of the multiple regression is defined by:

$$
\mathrm{Y}=\mathrm{X} \cdot \mathrm{B}+\varepsilon
$$

where: $\mathrm{Y}$ is a vector $\mathrm{n} \times 1$ of dependent variables, $\mathrm{X}$ is a matrix $\mathrm{n} x \mathrm{p}$ what contains the regression parameters, $\mathrm{B}$ is a vector $\mathrm{p} \times 1$ of independent variables, $\varepsilon$ is a vector $\mathrm{n} \times 1$ random disturbances, which have a zero mean value and constant variance.

\section{Basic concepts of the wavelet transform}

Let $f(x)$ is a continuous time series. The function $f$ is identified only through the series $\left\{X_{t}\right\}$, this series consists of discrete measurements at fixed intervals.

Sampled data $\left\{c_{0}, \mathrm{t}\right\}$ of series $\left\{X_{\mathrm{t}}\right\}$ represent a signal or time series $f(x)$ and it can be defined as the scalar product:

$$
c_{0, t}=\langle f(x), \phi(x-t)\rangle
$$

where $\phi(x)$ is a scaling function which corresponds to a low-pass filter and $t$ is the sample period.

Theses input data are decomposed into two sets: the wavelet coefficients (bandpass filtered components), plus the continuum or background or residual (a low-pass filtered version of theses data),

The scaling function is selected to satisfy the dilation equation:

$$
\frac{1}{2} \phi\left(\frac{x}{2}\right)=\sum_{k} h(k), \phi(x-k)
$$

where $h$ is a discrete low-pass filter associated with the scaling function.

The smoothed data $\left\{c_{\mathrm{j}, \mathrm{t}}\right\}$ at a specified resolution $j$ and at a position $t$ is the scalar product:

$$
c_{j, t}=\frac{1}{2^{j}}\left\langle f(x), \phi\left(\frac{x-t}{2^{j}}\right)\right\rangle
$$

This is obtained by the convolution:

$$
c_{j+1, t}=\sum_{k} h(k) \cdot c_{j, t+2^{j} k}
$$

The signal difference between two consecutive resolutions is:

$$
w_{j+1, t}=c_{j, t}-c_{j+1, t}
$$

which we can also write as:

$$
w_{j, t}=\frac{1}{2^{j}}\left\langle f(x), \psi\left(\frac{x-t}{2^{j}}\right)\right\rangle
$$

And the wavelet function is defined by:

$$
\frac{1}{2} \psi\left(\frac{x}{2}\right)=\phi(x)-\frac{1}{2} \phi\left(\frac{x}{2}\right)
$$

Equation 7 defines the discrete wavelet transform, for a resolution level $j$.

An approximation of the original signal, $c_{0}$, is a series of expansion which consists of the smoothed signal plus all the differences, for any time $t$,

$$
c_{0, t}=c_{J, t}+\sum_{j=1}^{J} w_{j, t}
$$

Note that the continuous signal should be well approximated by $X_{\mathrm{t}}$.

\section{Wavelets and prediction}

For most signals, low frequency content is the most important. The measured signal represents the wind speed, Fig. 1, has a low frequency content important for prediction and a high frequency content that brings together the gusts of wind, measurement errors, and a random component is difficult to predict.

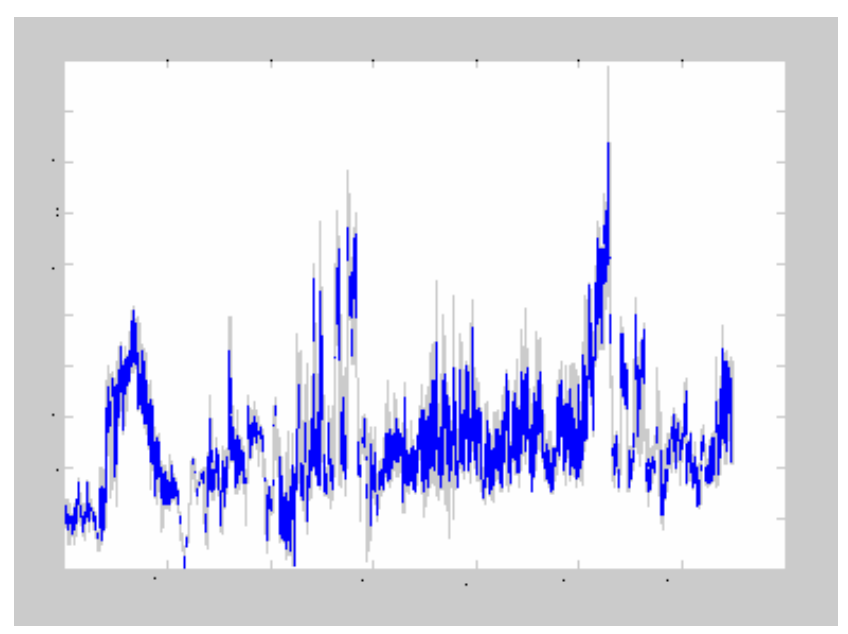

Fig. 1. Measured wind speed $(\operatorname{signal} S)$.

Each signal $S$, is decomposed into an approximation (low frequency part of the signal), $A$, and a detail (high frequency part of the signal), $D$, for each scale, Fig. 2. 


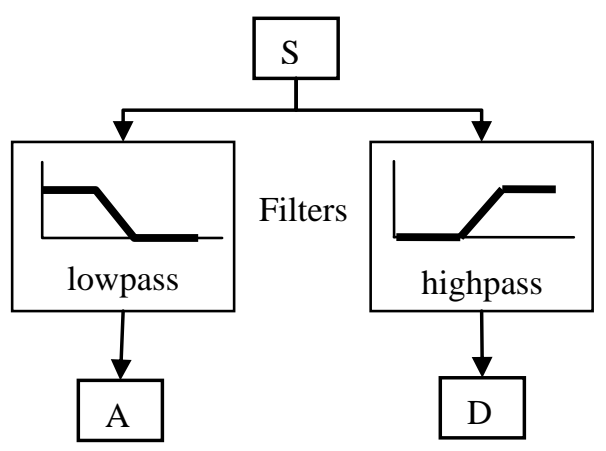

Fig. 2. Decomposition process

And this process of decomposition can be repeated iteratively, Fig 3.

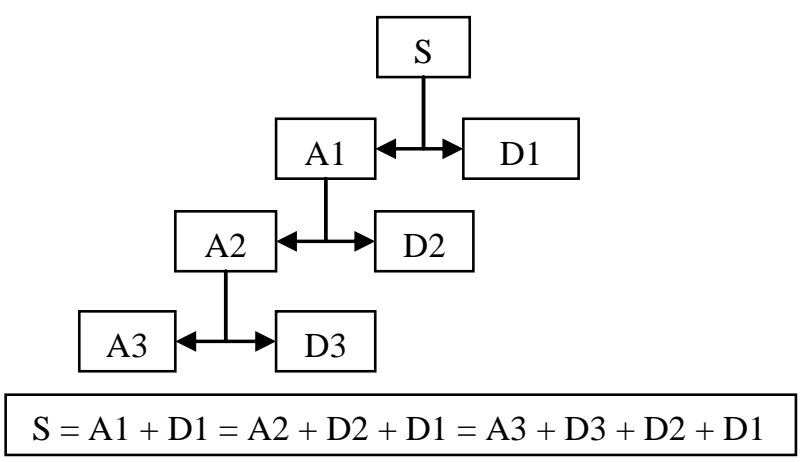

Fig. 3. Iterative decomposition.

In Fig. 4 we can see the approximation $A 3$ and detail D3, $D 2$ and $D 1$ of the signal in Fig. 1.

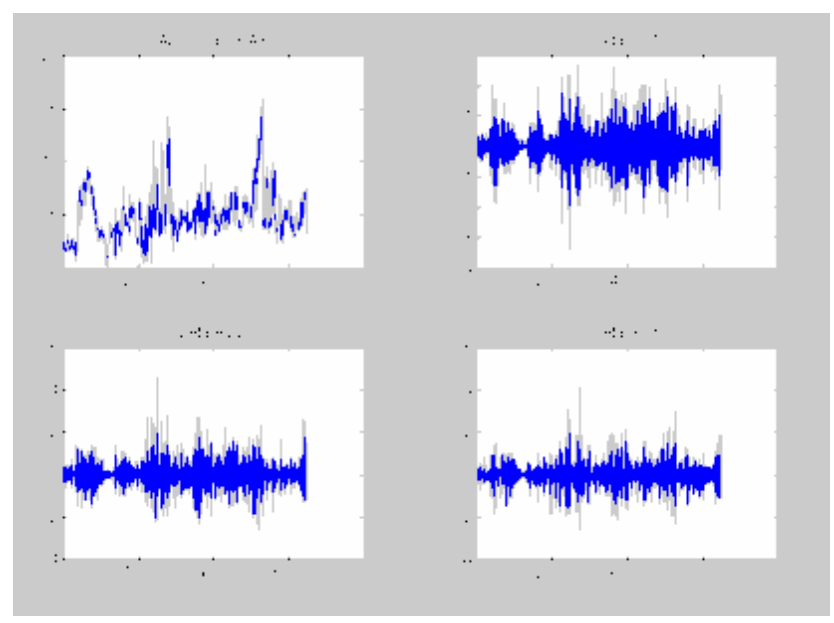

Fig. 4. Decomposition of the wind speed (Fig.1)

In our forecasting models have replaced $S$ for its approach $A$, and we have applied the method to forecast such an approach, ignoring the signal detail.. In Fig. 5 shows the original signal and the filtered signal used for forecasting.

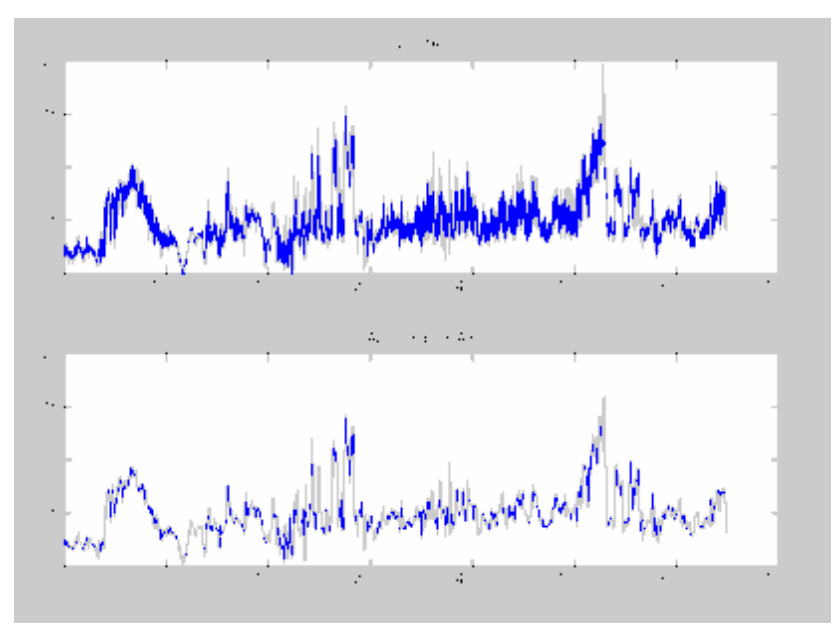

Fig. 5. Original and filtered signal.

\section{Results}

To carry out the study of models and filtering method, models are applied in two different situations: the first analyzes the forecast situation between 1 minute and 1 hour (using a range of wind speeds of 5 hours, a second difference between two consecutive speeds) and a second position to analyze the forecast from 2 hours and 1 day (using a range of wind speeds of $4 \frac{1}{2}$ days, with one minute difference between two consecutive speeds). In both situations, the results obtained are analyzed without applying any filtering, and applying the wavelet filter.

As a method of filtering has been used several families of wavelets and different levels of filtering. Tables II and III indicate the combination that best has resulted. For the prediction we used a regression model and as input variables wind speeds at times $\mathrm{t}-1, \mathrm{t}-2, \ldots, \mathrm{tn}$, depending on the number of values used.

As shown in Table II and III, the results improve significantly when wavelet filtering is applied to the series of wind speeds, because while the improvements made with the regression model against the persistence model ranges from the $-0.13268 \%$ and $10.3338 \%$ in Table II, and between $2.29799 \%$ and $20.9645 \%$ in Table III, the improvements obtained by applying wavelet filtering first and then the regression model range from $20.3773 \%$ to $51.4912 \%$ in Table II and between $27.0507 \%$ to $58.2939 \%$ in Table III. Moreover, the coefficient $\mathrm{R}^{2}$ is much higher in the filtering model (about 0.9) than in the unfiltered model (about 0.6), indicating that filtering made the relations between input and output more linear.

\section{Conclusion}

The results improve significantly when wavelet filtering is applied to the wind speeds series, because while the improvements made with neuronal model range from $1.37427 \%$ to $10.1596 \%$, the improvements obtained by applying wavelet filtering first and then the neural model range from $19.3369 \%$ to $48.7057 \%$. 
Table II .- Results obtained by applying the regression model at horizons less than 1 hour.

\begin{tabular}{|c|c|c|c|c|c|c|c|c|c|c|c|}
\hline \multirow{2}{*}{$\begin{array}{l}\text { horizon } \\
\text { temporal }\end{array}$} & \multirow{2}{*}{$\begin{array}{l}\text { time } \\
\text { step }\end{array}$} & \multirow{2}{*}{$\begin{array}{l}\mathrm{N}^{0} \\
\text { in. }\end{array}$} & \multicolumn{2}{|c|}{ wavelet filtered } & \multicolumn{2}{|c|}{$\overline{R^{2}}$} & \multicolumn{3}{|c|}{ RMSE errors } & \multicolumn{2}{|c|}{ improved VS persist. (\%) } \\
\hline & & & family & level & unfiltered & filtered & persist. & unfiltered & filtered & unfiltered & filtered \\
\hline 1 minute & 5 seconds & 5 & meyer & 3 & 0.660235 & 0.92822 & 1.25578 & 1.13372 & 0.76156 & 9.71925 & 39.3549 \\
\hline 5 minutes & 5 seconds & 1 & daubechies 2 & 4 & 0.637334 & 0.915092 & 1.01788 & 1.01923 & 0.81046 & -0.13268 & 20.3773 \\
\hline 5 minutes & 10 seconds & 5 & biorthogonal 2.8 & 5 & 0.639185 & 0.981226 & 1.28265 & 1.23027 & 0.68803 & 4.08443 & 46.3584 \\
\hline 5 minutes & 20 seconds & 1 & daubechies 3 & 7 & 0.612033 & 0.978427 & 1.28865 & 1.23271 & 0.70554 & 4.34042 & 45.2489 \\
\hline 10 minutes & 10 seconds & 6 & meyer & 4 & 0.645026 & 0.935808 & 1.25824 & 1.17959 & 0.61035 & 6.25005 & 51.4912 \\
\hline 10 minutes & 20 seconds & 2 & daubechies 5 & 6 & 0.632266 & 0.969259 & 1.28716 & 1.19681 & 0.72409 & 7.01935 & 43.7448 \\
\hline 10 minutes & 30 seconds & 2 & biorthogonal 5.5 & 6 & 0.635268 & 0.889336 & 1.29981 & 1.20032 & 0.69486 & 7.65367 & 46.5412 \\
\hline 20 minutes & 30 seconds & 2 & daubechies 2 & 6 & 0.629763 & 0.877906 & 1.26668 & 1.16196 & 0.6475 & 7.95185 & 48.8822 \\
\hline 20 minutes & 1 minute & 1 & daubechies 2 & 7 & 0.621027 & 0.860415 & 0.9733 & 0.95379 & 0.71852 & 2.00446 & 26.1775 \\
\hline 1 hour & 1 minute & 10 & biorthogonal 3.9 & 7 & 0.654126 & 0.986651 & 1.20783 & 1.08301 & 0.64997 & 10.3338 & 46.1866 \\
\hline
\end{tabular}

Table III .- Results obtained by applying the regression model in horizons between 2 and 24 hours.

\begin{tabular}{|c|c|c|c|c|c|c|c|c|c|c|c|}
\hline \multirow{2}{*}{$\begin{array}{l}\text { horizon } \\
\text { temporal }\end{array}$} & \multirow{2}{*}{$\begin{array}{l}\text { time } \\
\text { step }\end{array}$} & \multirow{2}{*}{$\begin{array}{l}\mathrm{N}^{0} \\
\text { in. }\end{array}$} & \multicolumn{2}{|c|}{ wavelet filtered } & \multicolumn{2}{|c|}{$\mathbf{R}^{2}$} & \multicolumn{3}{|c|}{ RMSE errors } & \multicolumn{2}{|c|}{ improved VS persist. (\%) } \\
\hline & & & family & level & unfiltered & filtered & persist. & unfiltered & filtered & unfiltered & filtered \\
\hline 2 hours & 5 minutes & 4 & symlet 4 & 3 & 0.833116 & 0.930506 & 0.91217 & 0.8654 & 0.48166 & 5.12777 & 47.1966 \\
\hline 2 hours & 10 minutes & 7 & coiflet 3 & 4 & 0.782005 & 0.928147 & 0.92546 & 0.83498 & 0.38597 & 9.77714 & 58.2939 \\
\hline 6 hours & 10 minutes & 7 & meyer & 4 & 0.782797 & 0.971094 & 0.73085 & 0.67236 & 0.39015 & 8.00296 & 46.6164 \\
\hline 6 hours & 30 minutes & 1 & daubechies 4 & 6 & 0.636656 & 0.773024 & 0.64706 & 0.63219 & 0.44421 & 2.29799 & 31.3486 \\
\hline 12 hours & 10 minutes & 9 & meyer & 4 & 0.785138 & 0.980212 & 0.68977 & 0.64827 & 0.27942 & 6.01672 & 59.4909 \\
\hline 12 hours & 30 minutes & 7 & symlet 5 & 6 & 0.653253 & 0.967708 & 0.73465 & 0.67181 & 0.35233 & 8.55275 & $\mathbf{5 2 . 0 4 0 8}$ \\
\hline 12 hours & 1 hour & 5 & coiflet 4 & 7 & 0.490387 & 0.958495 & 0.79682 & 0.72549 & 0.42445 & 8.9523 & 46.7313 \\
\hline 24 hours & 30 minutes & 4 & meyer & 6 & 0.603944 & 0.964729 & 1.57371 & 1.47507 & 0.69724 & 6.26845 & 55.6944 \\
\hline 24 hours & 1 hour & 4 & biorthogonal 3.9 & 7 & 0.498769 & 0.959468 & 2.02419 & 1.82567 & 0.95922 & 9.80772 & 52.612 \\
\hline 24 hours & 2 hours & 9 & daubechies 4 & 7 & 0.477881 & 0.629314 & 2.39672 & 1.89426 & 1.74839 & 20.9645 & 27.0507 \\
\hline
\end{tabular}

\section{Acknowledgement}

This work has been carried out within the Optimagrid project, supported by the Territorial Cooperation Program SUDOE Interreg IVB,

\section{References}

[1] Brown B.G., Katz R.W., Murphy A.H.: "Time Series Models to Simulate and Forecast Wind Speed and Wind Power", Journal of Climate and Applied Meteorology, Vol. 23, 1984.

[2] Bossanyi E.A.: "Short-Term Wind Prediction using Kalman Filters", Wind Engineering, Vol. 9, No. 1, 1985.

[3] Bossanyi E.A.: "Stochastic Wind Prediction for Wind Turbine System Control", Procd. Of the $7^{\text {th }}$ BWEA Wind Energy Conference, 27-29 March 1985.

[4] Djurovic M., Stankovic L.: "Predicition of Wind Characteristics in Short-Term Periods", Energy and Environment into de 1990s, Proceedings of the $1^{\text {st }}$ World Renewable Energy Congress, 1990.

[5] Fellows A., Hill D.: "Wind and Load Forecasting for Integration of Wind Power into a Meso-scale Electric Grid", Procd. Of the European Community Wind Energy Conf., EWEC'90, Madrid, Spain, 1990.

[6] Hill D. C., Feloows A.T., Hallyday J.A.: "Integration of Wind Power into a Meso-scale Electricity Grid", Procd. Of the $13^{\text {th }}$ British Wind Energy Association Conference 1991, Mechanical Engin. Publications Ltd., 1991.
[7] Contaxis G. C., Kabouris J.: "Short-Term Scheduling in a Wwind/Diesel Autonomous System", IEEE Trans. on Power System, 91

[8] Tande J. O. G., Landberg L.: "A $10 \mathrm{sec}$. Forecast of Wind Turbine Output with Neural Networks", Procd. Of the $4^{\text {th }}$ European Wind Energy Conference, ECWEC'93, LübeckTravemünde, Germany.

[9] Beyer H. G.: "Short-Term Prediction of Wind-Speed and Power Output of a Wind Turbine with Neural Networks", Procd. Of the $5^{\text {th }}$ European Community Wind Energy Conference, ECWEC'94, Thessaloniki, Greece, 1994.

[10] Lin L.: "Predicting Wind Behaviour with Neural Networks", Proc. Of the 1996 European Union Wind Energy Conference, EUWEC'96, Goteborg, Sweden, 1996.

[11] G. N. Kariniotakis, G.S. Stavrakakis, E.F. Nogaret: "Wind Power Forecasting Using Advanced Neural Networks Models", IEEE Transactions on Energy Conversion, Vol. 11, No. 4, December 1996.

[12] M. C. Alexiadis, P.S. Dokopoulos, H.S. Sahsamanoglou: "Wind Speed and Power Forecasting based on Spatial Correlation Models", IEEE Transactions on Energy Conversion, Vol. 14, No. 3, September 1999.

[13] Shuhui Li, Donald C. Wunsch, A. O'Hair, Michael G. Giesselmann: "Using Neural Networks to Estimate Wind Turbine Power Generation", IEEE Transactions on Energy Conversion, Vol. 16, No. 3, September 2001.

[14] P. Flores, A. Tapia, G. Tapia, "Application of a control algorithm for wind speed prediction and active power generation”, Renewable Energy, 30 (2005), 523-536.

[15] J.L. Torres, A. García, M. De Blas, A. De Francisco, "Forecast of hourly average wind speed with ARMA models in Navarre (Spain)", Solar Energy 79 (2005) 65-77. 